\title{
Assessment of the Requirements within the Environmental Monitoring Plans Used to Evaluate the Environmental Impacts of Desalination Plants in Chile
}

\author{
Iván Sola ${ }^{1, *} \mathbb{1}$, José Luis Sánchez-Lizaso ${ }^{1}$, Pamela T. Muñoz ${ }^{1,2,3}$, Enzo García-Bartolomei ${ }^{4,5}$, \\ Claudio A. Sáez ${ }^{2,6}$ and Domingo Zarzo ${ }^{7}$ \\ 1 Department of Marine Science and Applied Biology, University of Alicante, San Vicente del Raspeig s/n, \\ Alicante E-03080, Spain; jl.sanchez@ua.es (J.L.S.-L.); pamela.munoz@upla.cl (P.T.M.) \\ 2 Laboratory of Aquatic Environmental Research, Centro de Estudios Avanzados, Universidad de Playa \\ Ancha, Viña del Mar 2520000, Chile; claudio.saez@upla.cl \\ 3 Programa de Doctorado Interdisciplinario en Ciencias Ambientales, Facultad de Ciencias Naturales y \\ Exactas, Universidad de Playa Ancha, Valparaíso 2340000, Chile \\ 4 Programa de Doctorado en Ciencias Ambientales, Centro EULA, Universidad de Concepción, \\ Concepción 4030000, Chile; enzogarcia@udec.cl \\ 5 Centro de Recursos Hídricos para la Agricultura y Minería, Universidad de Concepción, \\ Concepción 4030000, Chile \\ 6 HUB-AMBIENTAL UPLA, Vicerrectoría de Investigación Postgrado e Innovación, Universidad de Playa \\ Ancha, Valparaíso 2340000, Chile \\ 7 Sacyr Agua, Paseo de la Castellana, 83-85, 28046 Madrid, Spain; dzarzo@sacyr.com \\ * Correspondence: ivan.sola@ua.es
}

Received: 14 August 2019; Accepted: 2 October 2019; Published: 6 October 2019

\begin{abstract}
Seawater desalination represents an alternative solution to face the challenge of water scarcity in Chile. However, the uncertainty toward potential environmental impacts of desalination plants represent a barrier to achieving water sustainability and socioeconomic development in Chile. This study aimed to assess the quality of environmental monitoring plans (EMP) and determine the aspects to be improved within it, in order to enhance the management of desalination plants during the operation phase and guarantee a sustainable development of the activity. The Environmental Impact Assessments (EIAs) and Environmental Impact Studies for seawater desalination projects published in the Environmental Impact Evaluation System (SEIA) in Chile between 1997 and 2018 were reviewed. The results of the brine production from desalination plants showed a significant increase in the last decade (about $1.6 \mathrm{Mm}^{3}$ per year estimated according to the projects approved or under implementation). The EMPs data show heterogeneity and increasing requirements over time, which can be attributed to the governmental effort to improve environmental protection. Furthermore, a high frequency of irrelevant descriptors was identified in the current EMPs. The study thus recommended standardizing the environmental requirements included in EMPs based on empiric scientific knowledge to enhance the environmental protection programs in Chile.
\end{abstract}

Keywords: environmental management plan; seawater desalination; environmental impact; brine discharge; reverse osmosis

\section{Introduction}

The continuous increase in global freshwater demand highlights the important role played by desalination to address water scarcity [1]. In Latin America, climate change poses critical challenges, 
among which water scarcity is one of the most important [2]. In Chile, which is highly affected by climate change [3,4], desalination of seawater using reverse osmosis has been proven to improve the social and economic sustainability of the country, because it can provide water for both human consumption and industrial activities. The industries in Chile, especially the copper and lithium mining industries, require very large quantities of water. In addition, Chile faces a critical challenge in providing water for the cities near to the Atacama Desert, which is considered the driest desert in the world. Owing to the geographic characteristics of Chile, with $6400 \mathrm{~km}$ of coastline and an average width of $180 \mathrm{~km}$, seawater desalination is considered the best alternative to solve current and future challenges regarding water scarcity in the country $[5,6]$.

The salinity of brine discharges from reverse osmosis plants is up to double that of seawater. In addition, they often contain chemicals used in the pretreatment and membrane cleaning processes. Some of these chemicals may be toxic to marine organisms [7]. Brine tends to accumulate on the benthic area near the outfall, due to its high density with respect to seawater, and it then moves toward deeper waters following the bottom bathymetry [8]. Therefore, it can induce stress responses in marine organisms, mainly benthic communities near the brine discharge [7,9-13]. Thus, these uncertainties regarding the environmental impacts of desalination on coastal systems represent a barrier to Chile's water sustainability and socioeconomic development.

In Chile, the environmental impact assessment process is perceived as an important legal instrument to pursue environmental protection, sustainable development, and marine conservation [14]. It is considered the most powerful management tool controlling environmental impacts from seawater reverse osmosis (SWRO) plants. However, normative and protocols related to SWRO plants are still under consideration. The environmental assessment process for the development of desalination plants in Chile began in 1997 through the Environmental Impact Evaluation System (Servicio de Evaluación de Impacto Ambiental, SEIA). Desalination projects submitted to SEIA could be assessed in two types of environmental assessment regarding the characteristics of these projects, as their specific effects or circumstances. Thus, projects with less involvement are being assessed through the Environmental Impact Assessment (Declaración de Impacto Ambiental, DIA), and projects with more involvement are being assessed through the Environmental Impact Study (Estudio de Impacto Ambiental, EIA) [14,15]. In [15], there are additional details about the environmental assessment process in Chile. Environmental monitoring plans (EMPs) ensure the effectiveness of the preventive and corrective measures established in DIAs or EIAs to protect marine environments [16]. EMPs can identify potential negative environmental impacts of desalination discharges and mitigate them by adopting adequate measures [11].

However, the weaknesses and gaps within the DIA or EIA frameworks must be fully understood and addressed. This study aims to assess the quality of EMPs and identify the process aspects that need improvement to achieve sustainable operation of desalination plants in Chile. This information can be used to conduct critical analyses to achieve the followings: (a) propose key environmental parameters that should be measured to identify the impacts of brine discharges, and (b) recognize the strengths and weaknesses within the current DIAs and EIAs frameworks in order to protect marine ecosystems from potential detrimental effects of the desalination industry.

\section{Materials and Methods}

A review of the DIAs and EIAs related to the construction and expansion of desalination projects in Chile was carried out based on the data compiled in the SEIA between 1997 and 2018 (http://seia.sea.gob.cl). A total of 24 desalination projects were identified, with three SWRO plants (IDs: 1,7 , and 15 in Table 1) that did not present EMPs for evaluation. Figure 1 shows the location of the desalination projects identified. Therefore, 21 EMPs for discharging brine effluents from SWRO plants were evaluated. 
Table 1. Publications of desalination projects approved by Chile's SEIA.

\begin{tabular}{|c|c|c|c|c|c|c|}
\hline ID & $\begin{array}{l}\text { Projects Approved or in } \\
\text { Operation Submitted to Chile's SEIA }\end{array}$ & Date & Typology & Region & $\begin{array}{c}\text { Freshwater } \\
\text { Production }\left(\mathrm{m}^{3} / \text { day }\right)\end{array}$ & $\begin{array}{l}\text { Time Project } \\
\text { (days) }\end{array}$ \\
\hline 2 & Taltal submarine emissary & $02 / 12 / 1998$ & EIA & II & 432 & 182 \\
\hline 4 & Agua de Mar Antofagasta desalination plant & $27 / 09 / 2001$ & DIA & II & 51840 & 118 \\
\hline 5 & Lixiviación de Sulfuros & $29 / 08 / 2003$ & EIA & II & 86400 & 242 \\
\hline 6 & Desalination plant implementation & $07 / 10 / 2004$ & DIA & II & 375 & 169 \\
\hline 7 & Piloto desalination plant & $18 / 10 / 2004$ & DIA & II & 45360 & 73 \\
\hline 9 & $\begin{array}{l}\text { Complementary Supply of Desalinated Water for } \\
\text { Minera Escondida }\end{array}$ & $12 / 06 / 2009$ & EIA & II & 276480 & 280 \\
\hline 10 & Hornitos desalination plant & $27 / 12 / 2010$ & DIA & II & 375 & 207 \\
\hline 11 & Desalinated Water Supply for Mantoverde & $13 / 05 / 2011$ & DIA & III & 10368 & 358 \\
\hline 12 & Planta Desalinizadora Minera Candelaria & $24 / 06 / 2011$ & EIA & III & 43200 & 330 \\
\hline 13 & Rural freshwater system. Chanavayita desalination plant & 09/03/2012 & DIA & I & 775 & 123 \\
\hline 14 & Sur Antofagasta desalination plant & 07/09/2012 & DIA & II & 86400 & 352 \\
\hline 15 & Mantos de la Luna second modification & $14 / 06 / 2013$ & DIA & II & 750 & 231 \\
\hline 16 & Update and Expansion of La Chimba Desalination Plant & $07 / 07 / 2014$ & DIA & II & 21600 & 336 \\
\hline 17 & Bahía Caldera desalination plant & $13 / 07 / 2015$ & DIA & III & 8000 & 581 \\
\hline 18 & Tocopilla desalination plant & $13 / 05 / 2016$ & DIA & II & 17280 & 449 \\
\hline 19 & $\begin{array}{l}\text { Región de Atacama, Provincias de Copiapó y Chañaral } \\
\text { desalination plant }\end{array}$ & $17 / 08 / 2016$ & EIA & III & 103680 & 392 \\
\hline 20 & Extension of Angamos Thermoelectric plant & $18 / 08 / 2016$ & EIA & II & 13680 & 622 \\
\hline 21 & Pisagua desalination plant & $12 / 07 / 2017$ & DIA & I & 345.6 & 567 \\
\hline 22 & Desalination plant and industrial water supply & $15 / 06 / 2017$ & DIA & II & 86400 & 685 \\
\hline 23 & Adaptation of the Desalination Plant RT Súlfuros & $09 / 03 / 2018$ & DIA & II & 168998 & 198 \\
\hline 24 & Guacolda desalination plant & $24 / 01 / 2018$ & DIA & III & 120956 & 225 \\
\hline
\end{tabular}
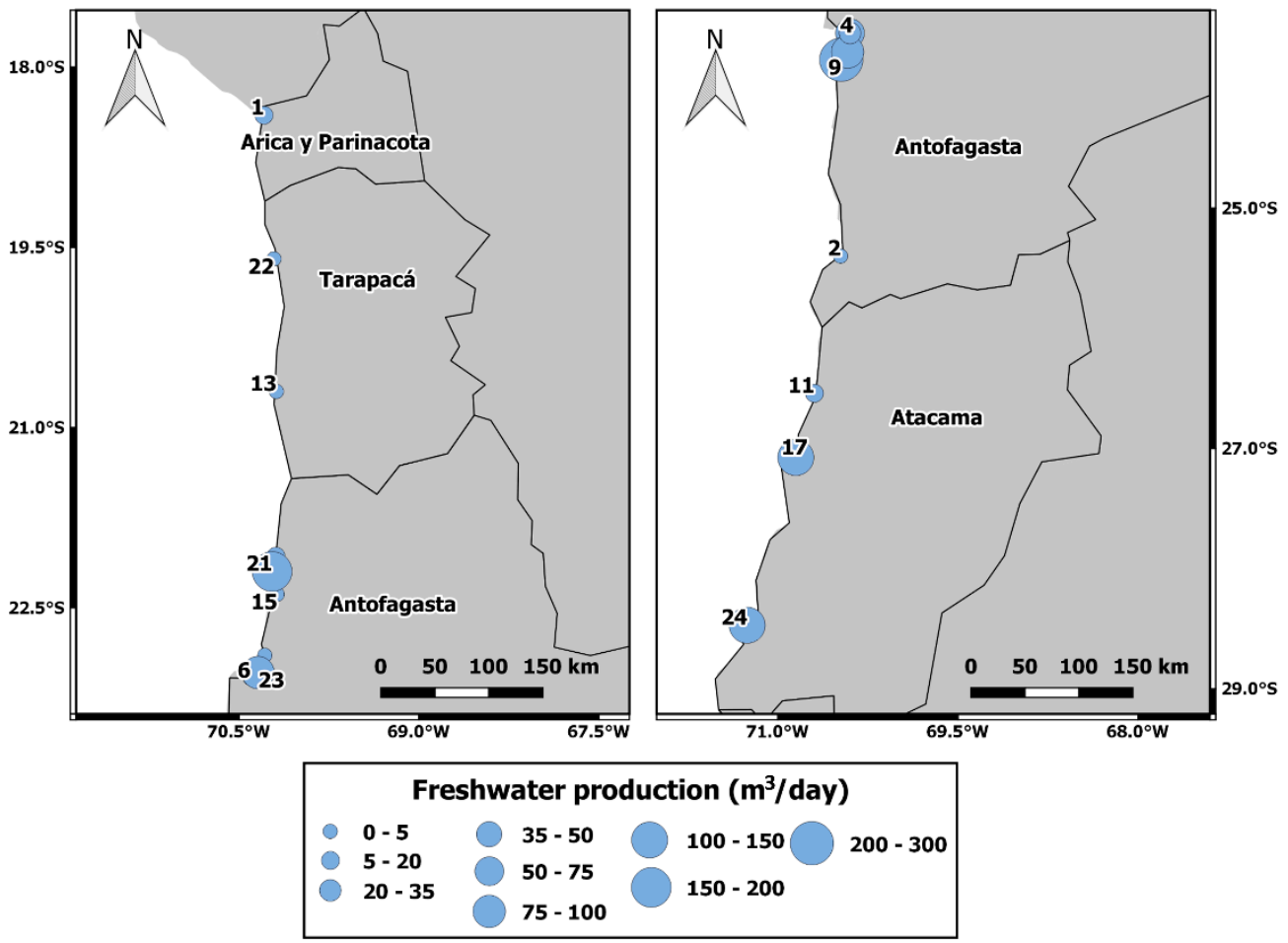

Figure 1. Location of desalination projects and their maximum production capacity $\left(\mathrm{m}^{3} /\right.$ day) submitted to the Environmental Impact Evaluation System (SEIA) between 1997 and 2018 in Chile.

The possible environmental impacts of each case were analyzed in order to perform adequate management of the brine discharges based on scientific criteria and achieve sufficient environmental protection. Thus, EMP requirements were specified according to the characteristics of the SWRO desalination plants and the marine ecosystem at the location of the brine effluent discharge.

The EMP requirements for monitoring the effects on marine ecosystems during the operation phase were identified. This approach also identifies the requirements for correct management of brine discharges [17] and some considerations related to the characteristics related the Chilean environment for sustainable management of SWRO desalinations plants during the operation phase. The important 
requirements highlighted by this approach include: $(\mathrm{i}, \mathrm{ii})$ analysis of the composition of the effluent water and seawater is advisable to control the substances present in the effluents-in particular, those caused by the pretreatment or cleaning of membranes, such as coagulants, antifouling compounds, and nutrients; (iii) determination of the saline plume extension, because it can help in specifying the area potentially affected by the discharge; (iv) using salinity-sensitive species as bio-indicators, which was proven to be useful, because they can provide information on possible impacts on benthic habitats and allow a discrimination between the effects of desalination and other impacts that may coincide in space, such as the effects of sewage discharges; (v) analysis of the ecological and chemical qualities of the sediments in order to quantify the impact on the benthic in the discharge area; (vi) conducting a structural monitoring of the submerged outfall for the early detection of possible fractures and leaks; and (vii) implementing a contingency plan that includes mitigation measures to control and correct the identified detrimental effects in cases when negative effects on benthic communities, such as infauna or sensitive species, are evidenced [8,10-12,16,18].

Additional considerations were included in this approach to adopt it within the Chilean environmental legislation according to the specific characteristics of the Chilean environment and marine communities. Firstly, (viii) the potential effects of seawater intake on plankton communities were incorporated. The effects of the brine effluent on plankton communities is unknown; nevertheless, plankton cannot survive during the seawater intake [12]. (ix) Moreover, toxicity testing is included in order to evaluate the effects of chemicals used in the pretreatment or membrane cleaning on the endemic species around the outfall area [19]. Finally, no protected species, such as P. oceanica in Spain or P. australis in Australia, were identified in the outfall area; hence, the evaluation of how the effluents affect them was not considered a requirement in the EMPs $[13,20]$.

The requirements extracted of each EMP were assessed using a semiquantitative scale (Table 2) following the method proposed by [17].

Table 2. Semiquantitative scale used for evaluating the environmental requirements of environmental monitoring plans (EMPs).

\begin{tabular}{c|c}
\hline Score & Assessment of Environmental Requirements of EMPs \\
\hline- & Absence of control, without environmental impact for its necessary control \\
4 & Control $100 \%$ of the parameter in the EMP \\
3 & Suboptimal control (control of $60-90 \%$ of the parameters in the EMP). Identified environmental impact on the marine environment \\
2 & Partially control (control of $40-60 \%$ of the parameters in the EMP). Identified environmental impact on the marine environment \\
1 & Insufficient control (control of $10-40 \%$ of the parameters in the EMP). Identified environmental impact on the marine environment \\
0 & Absence of control, identified environmental impact on the marine environment \\
\hline
\end{tabular}

Finally, the quality of each EMP was estimated using Equation (1) as follows:

$$
\text { EMP quality } y_{i}=\frac{\sum_{i}\left(E_{i, e}+S W_{i, e}+S P_{i, e}+S_{i, e, s}+B_{i, e, s}+O_{i, e, s}+C P_{i, e}+P K_{i, e, s}+T_{i, e}\right)}{\sum_{i}\left(E_{i}+S W_{i}+S P_{i}+P K_{i, s}+S_{i, s}+B_{i, s}+O_{i, s}+C P_{i}+P K_{i, s}+T_{i}\right)} \times 100 \%
$$

where $e$ is the evaluation of requirements considered for managing desalination plants during the operation phase of each EMP $i$, and $s$ is the necessary or unnecessary control parameters determined according to the characteristics of each desalination plant and the environment at the brine discharge location. The following parameters were considered according to these characteristics: the analysis of effluents and seawater quality $\left(E_{i}, S W_{i}\right)$, saline plume $\left(S P_{i}\right)$, analysis of sediment $\left(S_{i}\right)$, use of bio-indicators $\left(B_{i}\right)$, structural monitoring of the submerged outfall $\left(O_{i}\right)$, existence of contingency plan $\left(C P_{i}\right)$, analysis of plankton communities in the seawater intake area $P K_{i}$, and use of toxicological studies $\left(T_{i}\right)$.

Furthermore, sampling designs of each EMP were evaluated. Sampling process design is defined according to the spatial and temporal variability to avoid pseudo-replication and allow the detection of significant differences among samples [21,22]. Therefore, the following requirements were considered important for an adequate sampling design: (i) the spatial-temporal characteristics of the sampling 
design; (ii) the correct description of the procedure to carry out the analysis of requirements; (iii) and the inclusion of before-after-control-impact (BACI) to understand the environmental impacts of SWRO desalination plants on marine ecosystems [13].

In addition, irrelevant requirements were also evaluated. They are defined as those requirements that do not result in better control of the desalination plants during the operation phase and/or those with insignificant effects on the environment. These requirements are typically not based on scientific criteria and are not useful for managing SWRO plants during the operation phase [17]. Finally, linear regressions were performed to assess the incorporation of EMP requirements, irrelevant parameters and sampling design requirements over time, and relationships between EMP requirements and the production capacity of SWRO plants. Significant levels were set at $p<0.05$. R software was used to conduct statistical analyses and prepare graphs [23].

\section{Results}

\subsection{Current State of Desalination in Chile}

A total of 32 new constructed projects were submitted to DIA or EIA in Chile's SEIA from 1997 to 2018. A total of $75 \%$ of these projects were approved, $18.8 \%$ were not accepted or desisted, and only $6.3 \%$ are currently under assessment (Figure 2).

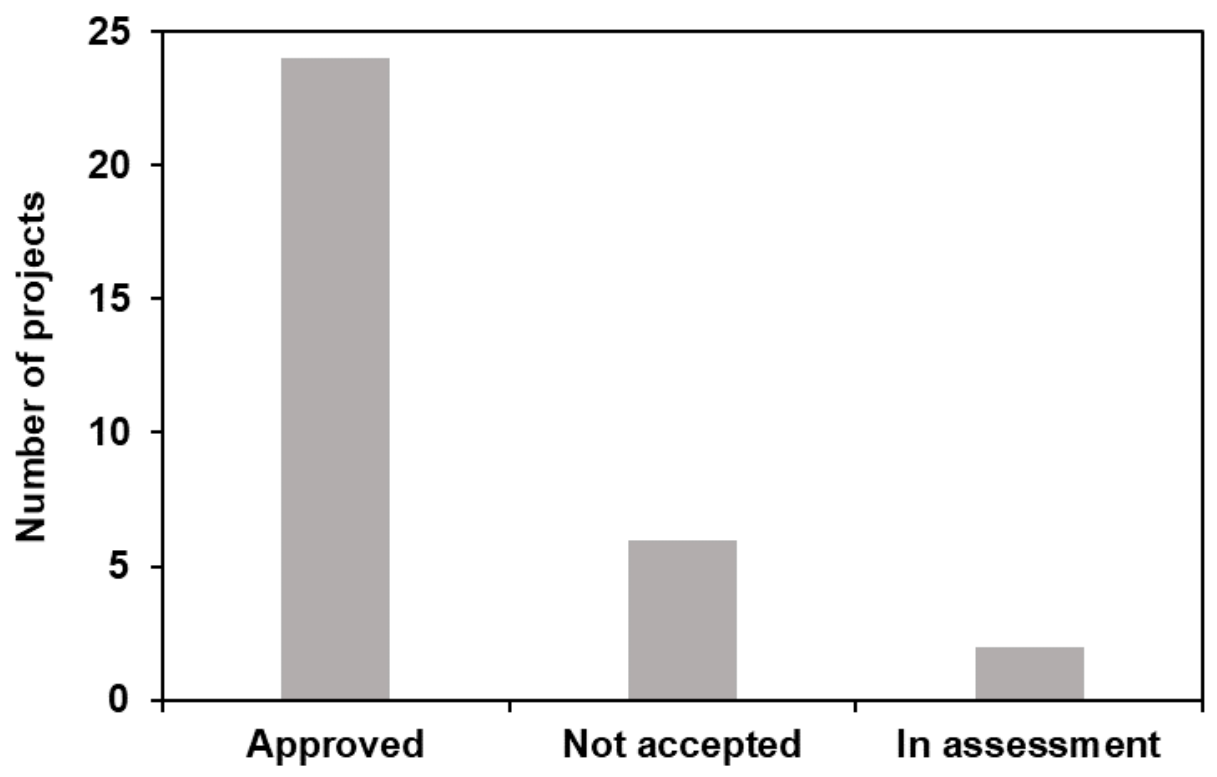

Figure 2. Number of desalination projects submitted to SEIA in Chile between 1997 and 2018 categorized by their status (approved, not accepted, and under assessment).

A total of 24 of the approved projects, which represent $62.5 \%$ of all approved projects between 2011 and 2018, were compiled (Figure 3). Among these, projects submitted to DIA and EIA represented $66.7 \%$ and $33.3 \%$, respectively, of the total (Table 1$)$. The majority of these projects $(66.7 \%)$ have been installed in the Antofagasta Region (Second region), while $20.8 \%$ of the approved projects are located in the Atacama (Third region). Currently, the extension of desalination to the central regions is under study. 


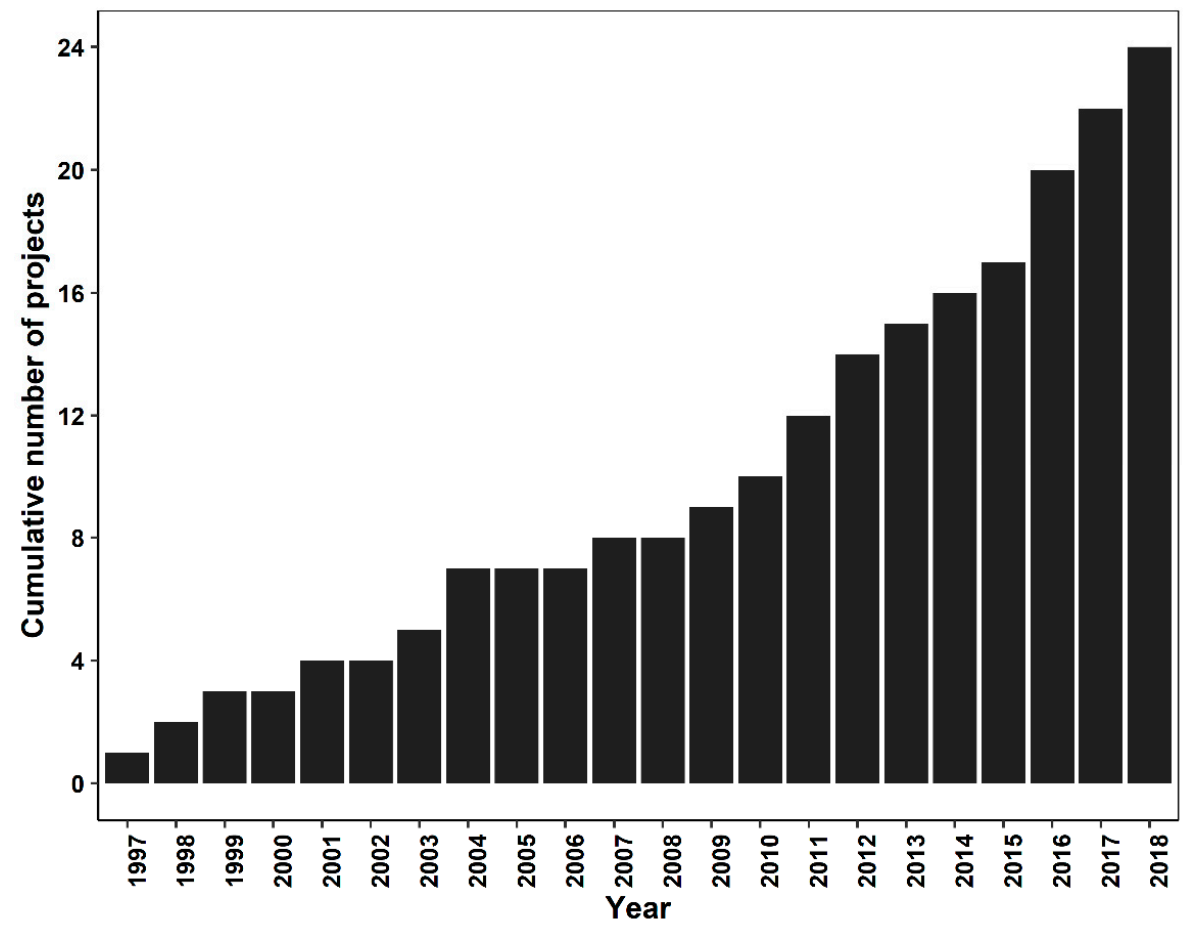

Figure 3. Cumulative number of desalination projects approved per year in Chile between 1997 and 2018.

The desalination sector in Chile is expanding at an increasing rate. This increase is divided between the private and public sectors (Figure 4). Desalination for public use started in 1997 and significantly increased from 2012. By contrast, desalination for industrial use started growing in 2003, which until 2011 represented 53\% of water production capacity for the industry, and continued to increase afterwards (Figure 4).

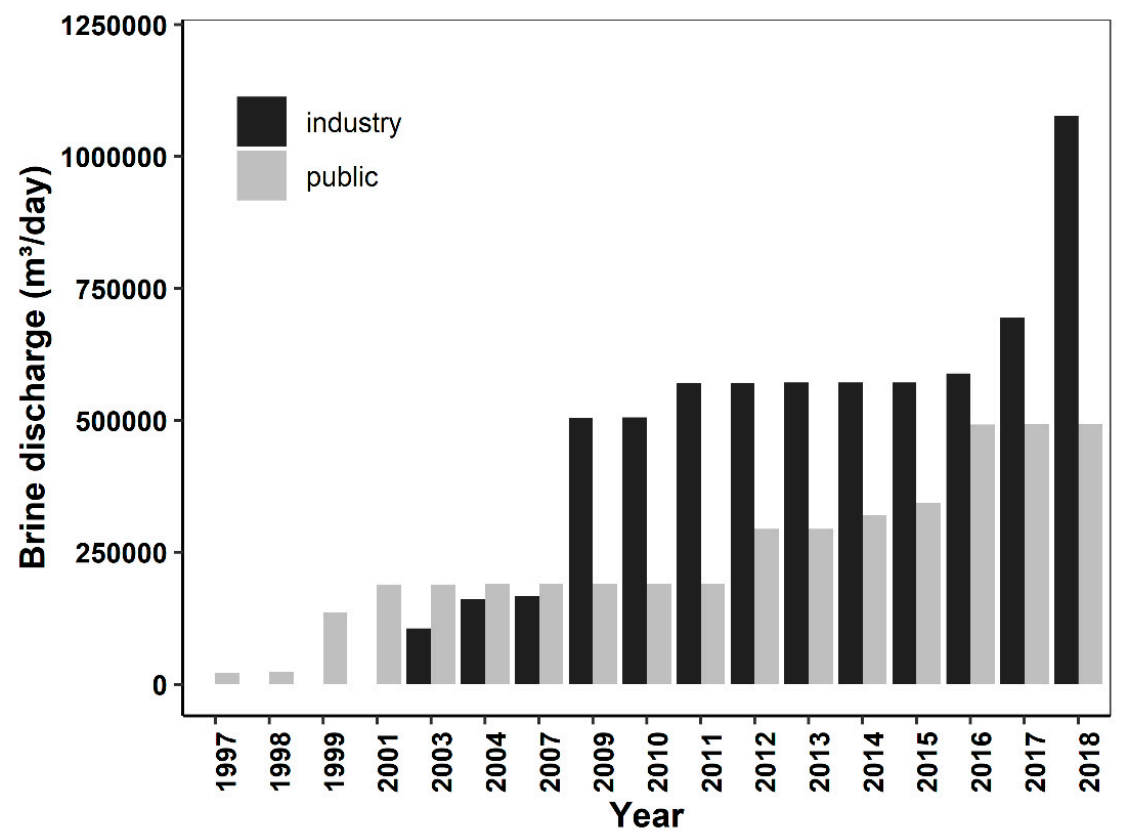

Figure 4. Assessment of the accumulated brine discharge production $\left(\mathrm{m}^{3} / \mathrm{day}\right)$ in the Chilean industrial and public sectors. 
The maximum production capacity among the projects evaluated was approximately $1.26 \mathrm{Mm}^{3} /$ day, which represents a maximum brine discharge capacity of nearly $1.57 \mathrm{Mm}^{3} /$ day, assuming an average plant conversion rate of $45 \%$ when brine production was not specified in the DIA or EIA [24].

Furthermore, the increasing development in the desalination industry in Chile caused an increase in the duration of environmental assessments. Thus, results showed a significant increase in the duration of the environmental assessment process over time in Chile $(p<0.01$, Figure 5). No significant differences were observed in the duration of the environmental assessment related with the different administrative procedure (DIA or EIA).

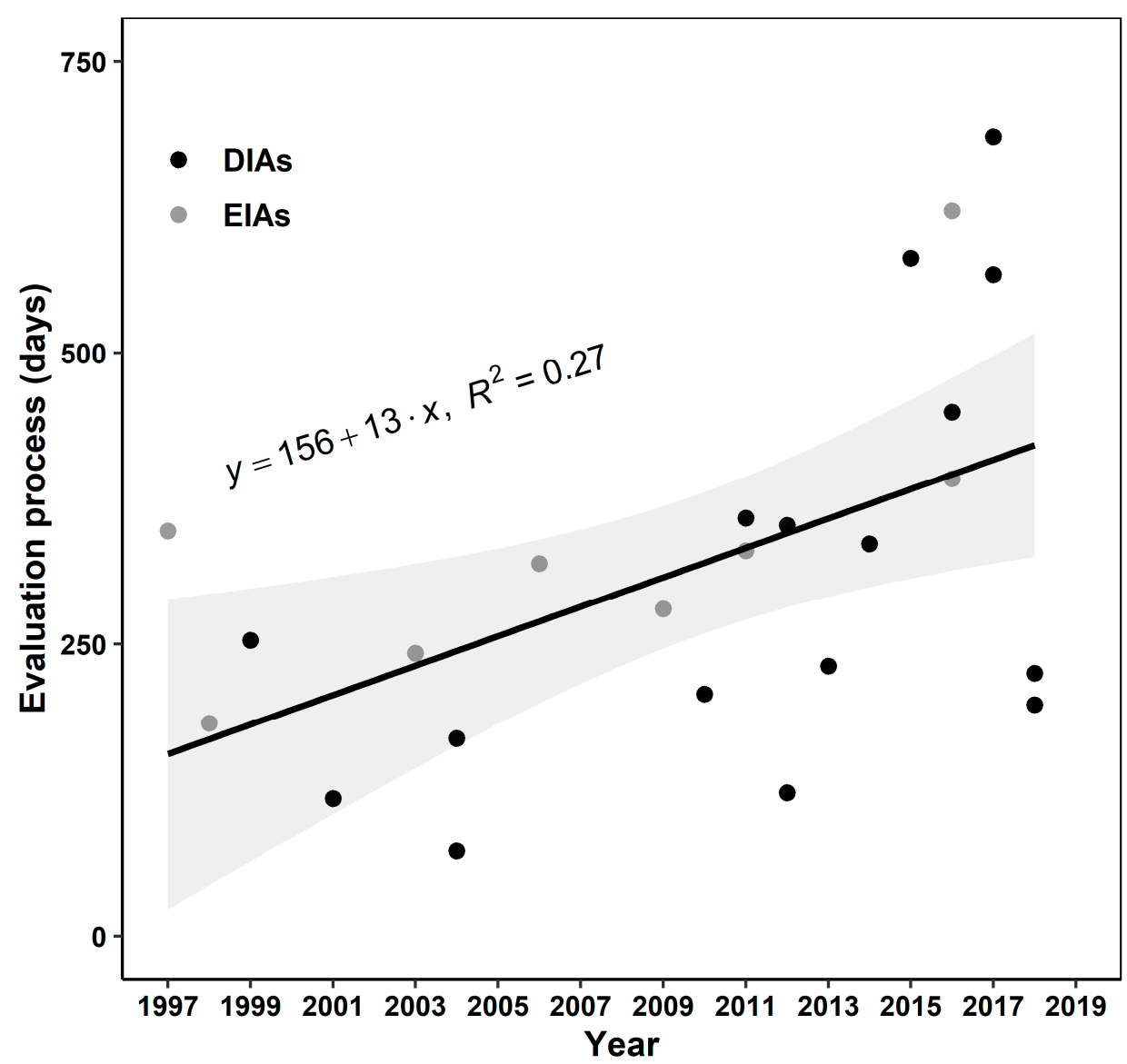

Figure 5. Linear regression between the period of the evaluation process (days) of projects and the publishing year in the SEIA.

\subsection{Environmental Requirements in the EMPs of Chile's Desalination Plants}

The results of the EMPs assessment show a high heterogeneity in the EMP requirements. Table 3 shows the analysis of EMP requirements for each project and the quality of the 21 EMPs evaluated.

The results of this study show a significant increasing trend in the environmental requirements within Chile's EMPs over time ( $p<0.01$; Figure 6 ). The highest environmental requirements reached 81.5\% in 2016 (ID: 18; Table 2), followed by those in 2011 (ID 11), 2017 (ID 22), and 2016 (ID 19, equivalent to more than $70 \%$ of requirements), respectively. By contrast, the lowest environmental requirements were identified in ID 4 (2001) with $21 \%$ of the requirements, followed by ID 10 (2010), ID 14 (2012), ID 5 (2003), and finally ID 2 (1998) with less than 30\% of the requirements. The EMPs assessed were found to have an average quality of $48.64 \%$. Furthermore, the relationship between maximum production capacity of SWRO plants and the requirements of EMPs was found to have high heterogeneity. This shows that there is no trend or relationship between plant capacity and environmental control requirements $(\mathrm{p}>0.05)$. 
Table 3. Assessment of the 21 EMPs using the parameters defined for the correct control and mitigation of the impacts caused by SWRO plants on the marine environment.

\begin{tabular}{|c|c|c|c|c|c|c|c|c|c|c|}
\hline ID & $\begin{array}{l}\text { Saline } \\
\text { Plume }\end{array}$ & $\begin{array}{c}\text { Bio- } \\
\text { Indicator }\end{array}$ & Plankton & Sediment & $\begin{array}{c}\text { Water } \\
\text { Quality }\end{array}$ & $\begin{array}{l}\text { Effluent } \\
\text { Quality }\end{array}$ & Bio-Toxicity & $\begin{array}{l}\text { Contingency } \\
\text { Plan }\end{array}$ & $\begin{array}{c}\text { Outfall } \\
\text { Inspection }\end{array}$ & $\begin{array}{c}\text { EMP } \\
\text { Quality }\end{array}$ \\
\hline 1 & - & - & - & - & - & - & - & - & - & - \\
\hline 2 & 0.67 & 0.00 & 0.00 & 0.83 & 1.00 & 0.17 & 0.00 & 0.00 & 0.00 & 29.63 \\
\hline 3 & 0.67 & 0.75 & 0.00 & 0.00 & 0.33 & 0.00 & 1.00 & 0.00 & 0.00 & 30.56 \\
\hline 4 & 0.67 & 0.75 & 0.00 & 0.00 & 0.33 & 0.17 & 0.00 & 0.00 & 0.00 & 21.30 \\
\hline 5 & 1.00 & 1.00 & 0.00 & 0.00 & 0.00 & 0.58 & 0.00 & 0.00 & 0.00 & 28.70 \\
\hline 6 & 1.00 & 0.00 & 0.00 & 1.00 & 1.00 & 0.54 & 1.00 & 0.00 & 0.00 & 50.46 \\
\hline 7 & - & - & - & - & - & - & - & - & - & - \\
\hline 8 & 1.00 & 0.50 & 1.00 & 0.67 & 0.33 & 0.00 & 0.00 & 0.00 & 0.00 & 38.89 \\
\hline 9 & 1.00 & 1.00 & 1.00 & 0.33 & 0.67 & 0.58 & 0.00 & 0.00 & 0.00 & 50.93 \\
\hline 10 & 0.67 & 0.50 & 0.00 & 0.33 & 0.00 & 0.58 & 0.00 & 0.00 & 0.00 & 23.15 \\
\hline 11 & 1.00 & 1.00 & 1.00 & 1.00 & 0.67 & 0.54 & 1.00 & 0.50 & 0.25 & 77.31 \\
\hline 12 & 1.00 & 0.75 & 1.00 & 0.67 & 0.33 & 0.17 & 0.00 & 0.00 & 0.50 & 49.07 \\
\hline 13 & 1.00 & 0.50 & 1.00 & 1.00 & 1.00 & 0.58 & 0.00 & 0.00 & 0.00 & 56.48 \\
\hline 14 & 1.00 & 0.50 & 0.00 & 0.33 & 0.33 & 0.17 & 0.00 & 0.25 & 0.00 & 28.70 \\
\hline 15 & - & - & - & - & - & - & - & - & - & - \\
\hline 16 & 1.00 & 1.00 & 1.00 & 0.33 & 0.50 & 0.17 & 1.00 & 0.25 & 0.00 & 58.33 \\
\hline 17 & 1.00 & 1.00 & 0.50 & 1.00 & 0.00 & 0.58 & 0.00 & 0.00 & 0.00 & 45.37 \\
\hline 18 & 1.00 & 1.00 & 1.00 & 0.33 & 0.33 & 0.92 & 1.00 & 0.75 & 1.00 & 81.48 \\
\hline 19 & 1.00 & 1.00 & 1.00 & 0.33 & 0.67 & 0.33 & 1.00 & 0.00 & 1.00 & 70.37 \\
\hline 20 & 1.00 & 1.00 & 1.00 & 0.67 & 0.33 & 0.00 & 0.00 & 0.00 & 0.00 & 44.44 \\
\hline 21 & 1.00 & 0.50 & 0.00 & 0.67 & 1.00 & 0.58 & 0.00 & 1.00 & 0.00 & 52.78 \\
\hline 22 & 1.00 & 1.00 & 1.00 & 0.33 & 0.75 & 0.33 & 0.00 & 1.00 & 1.00 & 71.30 \\
\hline 23 & 1.00 & 1.00 & 1.00 & 0.33 & 0.33 & 0.17 & 0.00 & 0.50 & 0.00 & 48.15 \\
\hline 24 & 1.00 & 0.50 & 1.00 & 1.00 & 0.33 & 0.54 & 0.00 & 0.75 & - & 64.06 \\
\hline Freq. (\%) & 93.65 & 72.62 & 59.52 & 53.17 & 48.81 & 36.71 & 28.57 & 23.81 & 18.75 & 48.64 \\
\hline
\end{tabular}

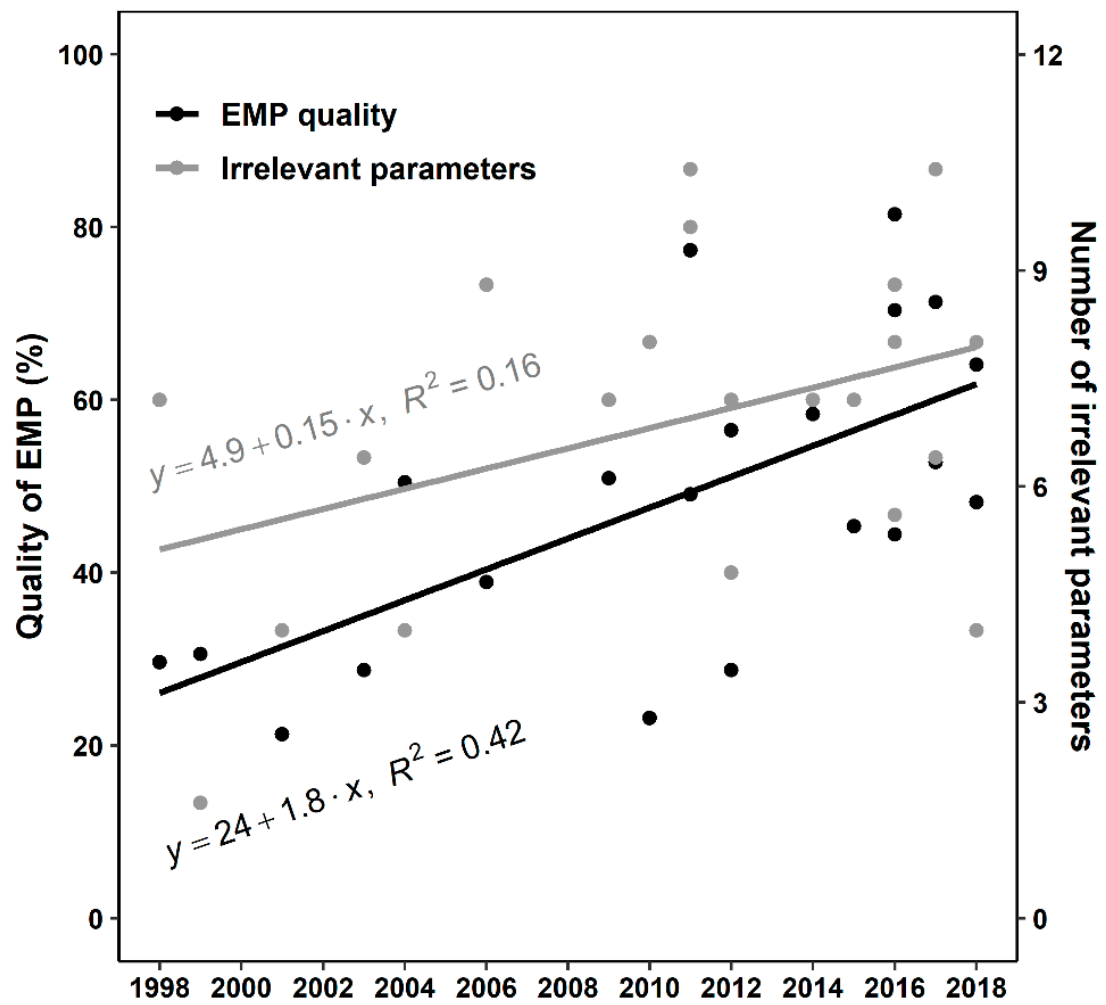

Figure 6. Linear regression between the number of environmental requirements in Chile's EMPs and the publishing year in the SEIA (black line) as well as the linear regression between the number of irrelevant parameters in EMPs and their publishing year (gray line).

In addition, a high heterogeneity was observed between the parameters included in the EMPs (Table 3). The parameters most frequently included in EMPs were the control of saline plume; bio-indicators; plankton; and sediment analyses, which were applied in $93.7 \%, 72.6 \%, 59.5 \%$, and 53.2\% of the EMPs, respectively. The parameters that were less frequently included in the EMPs were the analysis of seawater; assessment of effluent quality; development of bio-toxicological analysis of 
endemic species around the brine discharge area; a contingency plan for the brine discharge; and inspection of the submerged outfall, which were applied in $48.8 \%, 36.7 \%, 28.6 \%, 23.8 \%$, and $18.8 \%$ of the EMPs, respectively.

The results of EMPs distribution for each project evaluated showed that the Atacama Region had the highest requirements in the EMPs (61.2\%) followed by the Taracapá Region (54.6\%). Figure 7 shows the quality of EMPs based on the distribution of desalination plants in Chile.

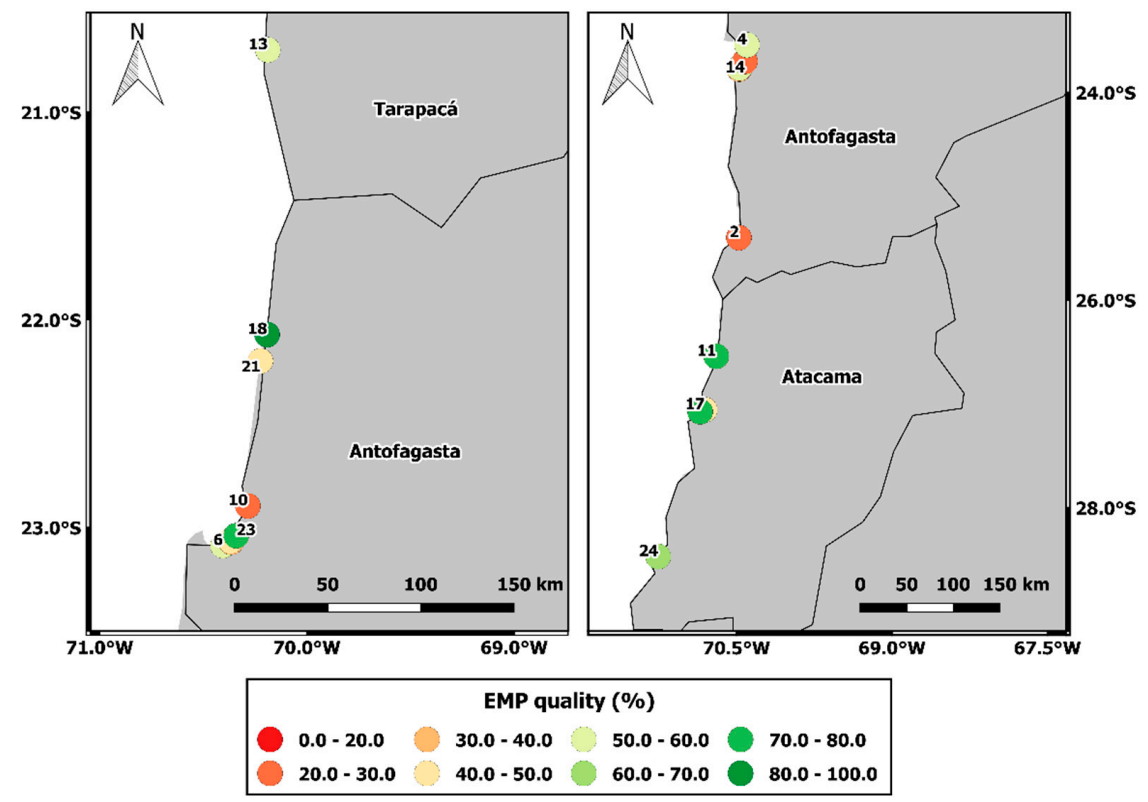

Figure 7. EMP quality assessed based on the distribution of desalination projects in Northern Chile.

In general terms, sampling designs defined in Chile's EMPs were found to be correctly established, since a $76 \% \pm 14.9$ general average was reached (Figure 8). In addition, linear regression between the sampling design requirements and the publishing year of each DIA/EIA showed a significant trend of improving in the EMP sampling designs over time $(\mathrm{p}<0.01)$.

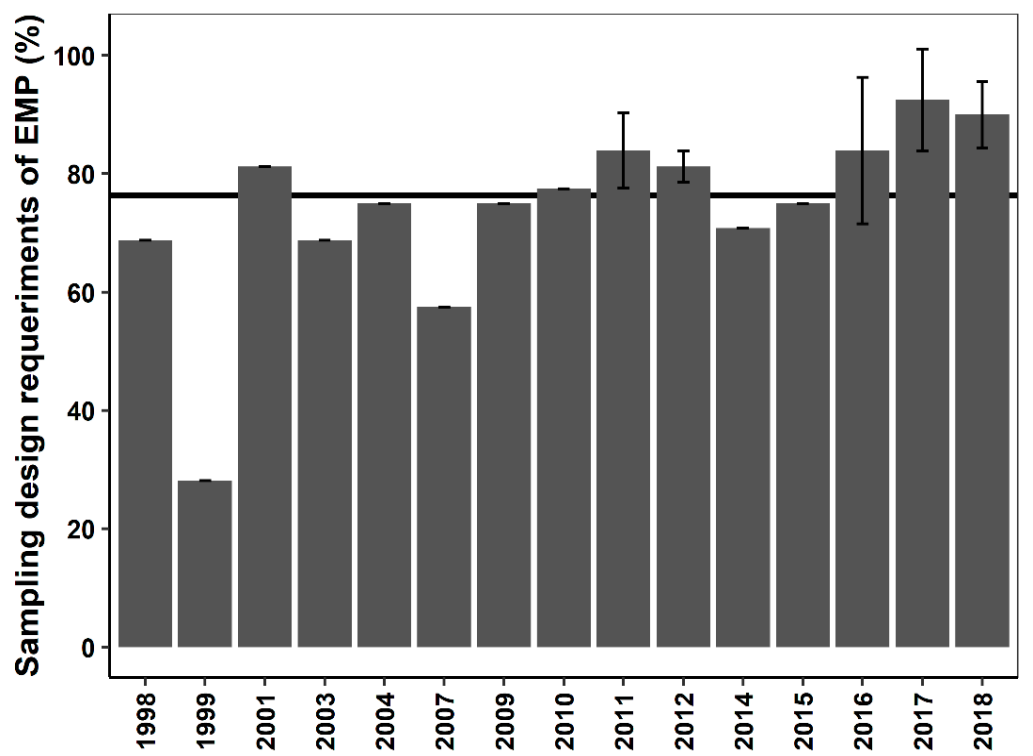

Figure 8. Mean values of sampling design requirements for each EMP assessed (bars represent standard deviation and solid black line indicates the general average). 


\subsection{Irrelevant Parameters Identified in EMPs}

The improvement in environmental requirements was found to be associated with a slightly increasing trend in irrelevant parameters in EMPs, although this trend was not significant $(p=0.07$; Figure 6). Table 4 shows the irrelevant parameters identified, i.e., those parameters that do not contribute to an accurate environmental diagnosis and protection. The average number of irrelevant parameters of EMPs reached seven.

Table 4. Irrelevant parameters identified in EMPs for each requirement.

\begin{tabular}{ccccccc}
\hline ID & Effluent & Seawater & Biological & Sediment & Others & Total \\
\hline 1 & 0 & 0 & 0 & 0 & 0 & 0 \\
2 & 0 & 6 & 2 & 0 & 0 & 8 \\
3 & 0 & 1 & 1 & 0 & 0 & 2 \\
4 & 4 & - & - & 0 & 0 & 4 \\
5 & 6 & 0 & 0 & 0 & 0 & 6 \\
6 & 1 & 1 & 1 & 0 & 1 & 4 \\
7 & 0 & 0 & 0 & 0 & 0 & 0 \\
8 & 0 & 4 & 0 & 3 & 0 & 7 \\
9 & 6 & 0 & 1 & 0 & 0 & 7 \\
10 & 6 & 0 & 1 & 0 & 1 & 8 \\
11 & 0 & 5 & 3 & 2 & 1 & 11 \\
12 & 4 & 5 & 1 & 1 & 0 & 11 \\
13 & 5 & 2 & 0 & 0 & 0 & 7 \\
14 & 3 & 0 & 1 & 0 & 0 & 4 \\
15 & 0 & 0 & 0 & 0 & 0 & 0 \\
16 & 3 & 2 & 0 & 2 & 0 & 7 \\
17 & 6 & 0 & 1 & 0 & 0 & 7 \\
18 & 6 & 2 & 0 & 0 & 0 & 8 \\
19 & 0 & 4 & 1 & 0 & 2 & 7 \\
20 & 0 & 4 & 0 & 3 & 0 & 7 \\
21 & 6 & 3 & 1 & 1 & 0 & 11 \\
22 & 4 & 2 & 1 & 0 & 0 & 7 \\
23 & 4 & 0 & 0 & 0 & 0 & 4 \\
24 & 4 & 4 & 0 & 1 & 0 & 9 \\
\hline Total & $\mathbf{6 8}$ & $\mathbf{4 5}$ & $\mathbf{1 5}$ & $\mathbf{1 3}$ & $\mathbf{5}$ & $\mathbf{1 4 6}$ \\
\hline & & & & & & \\
\hline
\end{tabular}

The maximum number of descriptors found within the irrelevant parameters identified after the assessment of the quality of the effluent represented $46.6 \%$ of the total. These parameters are mainly associated with the analysis of fats and oils, hydrocarbons, metals, and coliforms. A $30.8 \%$ of the irrelevant parameters determined in seawater were found to be associated with of the concentration of metals, coliforms, hydrocarbons, foaming power, etc., while $10.3 \%$ of the irrelevant parameters were related to monitoring intertidal and littoral communities and associated sediments. Finally, 8.9\% of the total irrelevant parameters corresponded to physicochemical description of sediments (e.g., concentration of metals, hydrocarbons, sulfur content, and surface carbon particles), and the other $3.4 \%$ were associated with the monitoring of other parameters, such as oceanographic and atmospheric characterization near the brine discharge (refer to Tables A1-A5 in Appendix A).

\section{Discussion}

The analysis of projects submitted to SEIA provided a perspective of the brine production expected from the operative and projected SWRO plants in Chile. In the last decade, the production capacity of desalinated water in the country has notably increased, representing $77 \%$ of the total production of freshwater, and used for different applications [25]. However, this significant development results in huge brine effluents delivered to the marine environment. Desalination is considered an important solution to solve the problem of water scarcity in Chile, especially for semiarid and arid areas (Central 
and Northern Chile). Moreover, $68 \%$ of the total production capacity evaluated is aimed at the industrial sector. However, there has been a marked increase in the production of desalinated water for the public sector since 2012. Water supplies in the semiarid and arid zones are intensified by the huge freshwater demand for industrial applications, especially in the mining industry [25]. Moreover, the number of desalination projects is expected to increase toward the south as a result of the accompanied climate change-driven displacement of the Atacama Desert [2]. The investigations conducted in this study demonstrate that about $88 \%$ of the projects in the Antofagasta and Atacama Regions have been submitted to SEIA, which include those approved or currently subjected to evaluation.

This increase in desalinated water production may cause negative impacts on the marine ecosystems with incorrect environmental management of the SWRO plants operation as a result of the brine discharges $[12,13]$. The results show that the brine discharge production in Chile was about $1.6 \mathrm{Mm}^{3} /$ day from all desalination projects currently operating or under the SEIA consideration. Thus, there is an urgent need for correct implementation of EMPs for desalination projects in order to ensure the environmental protection of the locations, where the currently operating plants discharge their effluents, facilitate the installation of new SWRO projects, and increase their economic viability through only focusing on the parameters that are environmentally relevant.

The significant increasing trend in the control requirements within EMPs over time in all 21 EMPs evaluated reflects an awareness of the local authorities (led by the Ministry of the Environment of Chile) to solve the water scarcity crises through environmentally sustainable practices. However, environmentally relevant parameters in current EMPs reached only $48.6 \%$ of the total requirements. Thus, improvements, especially related to monitoring the seawater and brine qualities by including biological tools for environmental diagnosis, are necessary (e.g., assessment of bio-indicators, biomarkers, and/or stress responses) using local species; contingency plans to apply mitigation measures when environmental impacts are identified; and frequent outfall inspection for the early detection of possible leaks or fractures. These are highlighted as the main considerations for future EMPs, because they are only considered in $50 \%$ of the current EMPs.

Similar results were obtained in the study conducted by [17], which showed a significant trend in improving the environmental requirements and sampling designs in Spain's EMPs; however, the majority of EMPs in Spain displayed less appropriate sampling designs compared to the Chilean EMPs. A good sampling design allows better detection of potential negative effects on the marine environment, so that they can be mitigated and controlled [11]. To address the latter, it is essential to increase spatial/temporal variabilities in the environmental requirements of the assessment conducted in the affected area of the brine discharge and in control locations [13].

Although DIA is a relative brief procedure compared with EIA [14], no significant differences were found between them in the period of evaluation or in requirements included in EMPs for desalination projects analyzed.

A number of disadvantages have been identified in the assessment of EMPs in Chile. For instance, no relation was found between the environmental requirements and the increase in the brine discharge from SWRO plants. However, an increase in the brine production may lead to creation of saline plumes and an increase in the affected area [8]. Similarly, an increase in the freshwater production is related to an increase in the seawater intake capacity, which could affect the surrounding plankton communities [12]. On the other hand, the irrelevant parameters (77.4\% of the total) are better suited to other types of effluents, such as sewage and wastewaters from agriculture [26], but not from the SWRO plant operation.

In terms of biomonitoring, it is important to adopt requirements that focus on species with high probability of occurrence in the affected area. SWRO plants evaluated in this study use submerged outfalls as discharge method; thus, monitoring the intertidal and littoral communities, which are unlikely to be affected, has little value to the environmental diagnosis $[8,27]$. Including these irrelevant parameters in the assessment increases the cost of EMPs and does not offer valuable information. 
There are a lot of relevant studies in the literature documenting impacts from desalination discharges. However, the available published information is of little use in the evaluation of impacts on Chilean coastal systems. Model species, for which impacts are examined in these studies, have a completely different ecological structure and potential tolerance thresholds compared to the marine communities of the Humboldt system dominant in the Chilean coastline. Therefore, it is difficult to envision recommendations for sustainable and biologically nonthreatening operation to be incorporated in the EMPs, due to the absence of toxicological assessments on local species and communities. Considering that only $28.5 \%$ of the EMPs assessed implement these analyses, further investigations are required to generate basic information on biological effects of brines on Chilean coastal communities, which are valuable information for the development of up-to-date biomonitoring protocols to achieve accurate and reliable environmental diagnosis. These actions are essential to keep up with the fast growth of the SWRO industry in Chile that is expected to further increase due to climate change. However, according to the international experience in Spain and Australia, negative impacts of SWRO discharges on the marine environment caused by the development in desalination sector can be efficiently mitigated $[9,11,12,28,29]$.

Research has proven that marine macrophytes are a suitable species for biomonitoring that can reflect the impacts of the desalination industry-for example, marine angiosperms including Posidonia oceanica found in the Mediterranean Sea [20,30,31] or Posidonia australis found in Australia [32]. In addition, the authors of [17] showed that areas with protected species, such as P. oceanica, indicated greater environmental requirements in their EMPs for monitoring the effect of brine effluents on marine ecosystems. This, added to their ecological relevance as a base of trophic networks, suggests that macroalgae and kelp forests, since they are dominant in Chilean coastal ecosystems, would make good candidates for future eco-toxicological assessments regarding brine discharge impacts in Chile [33].

\section{Conclusions}

The assessment of the requirements stated in the Chilean EMPs revealed a high heterogeneity between projects and indicates that it needs to be improved and updated according to sound scientific evidence. The significant increasing trend in the control requirements within EMPs over time reflects an increasing awareness of the local authorities to solve the water scarcity crises through environmental sustainability. However, a review of EMPs is necessary to include all relevant requirements when they are absent and eliminate irrelevant descriptors that are not related to better protection of marine ecosystems. This will ensure real environmental protection and avoid unnecessary economic losses due to the study of irrelevant, and sometimes costly, descriptors. Finally, special consideration should be taken of EMPs for plants with high water production, which are the most likely to induce environmental impacts.

Author Contributions: Conceptualization, J.L.S.-L., D.Z., and C.A.S.; methodology, I.S.; formal analysis, I.S. and J.L.S.-L.; investigation, I.S., P.T.M. and E.G.-B.; data curation, I.S.; writing-original draft preparation, I.S.; writing-review and editing, all authors; supervision, C.A.S. and J.L.S.-L.; funding acquisition, D.Z. and C.A.S.

Funding: I.S. has a grant funded by University of Alicante and Sacyr Agua S.L. Also, P.T.M. and C.A.S were funded by project CEA 01-1819 from Convenio Desempeño UPA 1795 granted to Universidad de Playa Ancha. E.G.-B. is funded by CONICYT doctoral scholarship and has grant from the IDA Channabasappa Memorial Scholarship.

Conflicts of Interest: The authors declare no conflict of interest. 


\section{Appendix A Irrelevant Parameters by Monitoring Area}

Table A1. Irrelevant descriptors identified in the effluent monitoring.

\begin{tabular}{|c|c|c|c|c|c|c|c|}
\hline ID & Fat/oils & Hydrocarbons & Metals & Coliforms & Phenols & Chloroethenes/Methanes & Total \\
\hline 1 & - & - & - & - & - & - & - \\
\hline 2 & 0 & 0 & 0 & 0 & 0 & 0 & 0 \\
\hline 3 & 0 & 0 & 0 & 0 & 0 & 0 & 0 \\
\hline 4 & 1 & 1 & 1 & 0 & 1 & 0 & 4 \\
\hline 5 & 1 & 1 & 1 & 1 & 1 & 1 & 6 \\
\hline 6 & 1 & 0 & 0 & 0 & 0 & 0 & 1 \\
\hline 7 & - & - & - & - & - & - & - \\
\hline 8 & 0 & 0 & 0 & 0 & 0 & 0 & 0 \\
\hline 9 & 1 & 1 & 1 & 1 & 1 & 1 & 6 \\
\hline 10 & 1 & 1 & 1 & 1 & 1 & 1 & 6 \\
\hline 11 & 0 & 0 & 0 & 0 & 0 & 0 & 0 \\
\hline 12 & 1 & 1 & 1 & 0 & 1 & 0 & 4 \\
\hline 13 & 1 & 1 & 1 & 1 & 1 & 0 & 5 \\
\hline 14 & 1 & 1 & 0 & 1 & 0 & 0 & 3 \\
\hline 15 & & - & - & - & - & - & \\
\hline 16 & 1 & 1 & 0 & 1 & 0 & 0 & 3 \\
\hline 17 & 1 & 1 & 1 & 1 & 1 & 1 & 6 \\
\hline 18 & 1 & 1 & 1 & 1 & 1 & 1 & 6 \\
\hline 19 & 0 & 0 & 0 & 0 & 0 & 0 & 0 \\
\hline 20 & 0 & 0 & 0 & 0 & 0 & 0 & 0 \\
\hline 21 & 1 & 1 & 1 & 1 & 1 & 1 & 6 \\
\hline 22 & 1 & 1 & 1 & 0 & 1 & 0 & 4 \\
\hline 23 & 1 & 1 & 1 & 0 & 1 & 0 & 4 \\
\hline 24 & 1 & 1 & 1 & 1 & 0 & 0 & 4 \\
\hline Total & 15 & 14 & 12 & 10 & 11 & 6 & 68 \\
\hline
\end{tabular}

Table A2. Irrelevant descriptors identified in the seawater monitoring.

\begin{tabular}{|c|c|c|c|c|c|c|c|c|c|c|}
\hline ID & Metals & Coliforms & $\begin{array}{c}\text { Foaming } \\
\text { Power }\end{array}$ & Hydrocarbons & Fat/Oils & Phenols & Chlorophyll & HAT/Color & $\begin{array}{c}\text { Carbon/Organic } \\
\text { Matter }\end{array}$ & Total \\
\hline 1 & - & - & - & - & - & - & - & - & - & - \\
\hline 2 & 1 & 1 & 1 & 1 & 1 & 0 & 0 & 1 & 0 & 6 \\
\hline 3 & 1 & 0 & 0 & 0 & 0 & 0 & 0 & 0 & 0 & 1 \\
\hline 4 & 0 & 0 & 0 & 0 & 0 & 0 & 0 & 0 & 0 & 0 \\
\hline 5 & 0 & 0 & 0 & 0 & 0 & 0 & 0 & 0 & 0 & 0 \\
\hline 6 & 0 & 0 & 0 & 0 & 1 & 0 & 0 & 0 & 0 & 1 \\
\hline 7 & - & - & - & - & - & - & - & - & - & - \\
\hline 8 & 1 & 1 & 0 & 0 & 0 & 0 & 0 & 1 & 1 & 4 \\
\hline 9 & 0 & 0 & 0 & 0 & 0 & 0 & 0 & 0 & 0 & 0 \\
\hline 10 & 0 & 0 & 0 & 0 & 0 & 0 & 0 & 0 & 0 & 0 \\
\hline 11 & 1 & 0 & 1 & 1 & 1 & 1 & 0 & 0 & 0 & 5 \\
\hline 12 & 1 & 0 & 1 & 1 & 1 & 1 & 0 & 0 & 0 & 5 \\
\hline 13 & 0 & 1 & 0 & 0 & 1 & 0 & 0 & 0 & 0 & 2 \\
\hline 14 & 0 & 0 & 0 & 0 & 0 & 0 & 0 & 0 & 0 & 0 \\
\hline 15 & - & - & - & - & - & - & - & - & - & - \\
\hline 16 & 1 & 0 & 0 & 0 & 0 & 0 & 1 & 0 & 0 & 2 \\
\hline 17 & 0 & 0 & 0 & 0 & 0 & 0 & 0 & 0 & 0 & 0 \\
\hline 18 & 0 & 1 & 1 & 0 & 0 & 0 & 0 & 0 & 0 & 2 \\
\hline 19 & 0 & 0 & 1 & 1 & 0 & 1 & 1 & 0 & 0 & 4 \\
\hline 20 & 1 & 1 & 0 & 0 & 0 & 0 & 0 & 1 & 1 & 4 \\
\hline 21 & 1 & 1 & 0 & 0 & 0 & 0 & 1 & 0 & 0 & 3 \\
\hline 22 & 1 & 0 & 0 & 1 & 0 & 0 & 0 & 0 & 0 & 2 \\
\hline 23 & 0 & 0 & 0 & 0 & 0 & 0 & 0 & 0 & 0 & 0 \\
\hline 24 & 1 & 1 & 1 & 1 & 0 & 0 & 0 & 0 & 0 & 4 \\
\hline Total & 10 & 7 & 6 & 6 & 5 & 3 & 3 & 3 & 2 & 45 \\
\hline
\end{tabular}


Table A3. Irrelevant descriptors identified in the monitoring of biological parameters.

\begin{tabular}{|c|c|c|c|c|c|}
\hline ID & Intertidal Communities & Littoral Communities & Intertidal Sediments & Littoral Sediments & Total \\
\hline 1 & - & - & - & - & - \\
\hline 2 & 1 & 0 & 1 & 0 & 2 \\
\hline 3 & 1 & 0 & 0 & 0 & 1 \\
\hline 4 & 0 & 0 & 0 & 0 & - \\
\hline 5 & 0 & 0 & 0 & 0 & 0 \\
\hline 6 & 0 & 1 & 0 & 0 & 1 \\
\hline 7 & - & - & - & - & - \\
\hline 8 & 0 & 0 & 0 & 0 & 0 \\
\hline 9 & 1 & 0 & 0 & 0 & 1 \\
\hline 10 & 1 & 0 & 0 & 0 & 1 \\
\hline 11 & 1 & 1 & 0 & 1 & 3 \\
\hline 12 & 1 & 0 & 0 & 0 & 1 \\
\hline 13 & 0 & 0 & 0 & 0 & 0 \\
\hline 14 & 1 & 0 & 0 & 0 & 1 \\
\hline 15 & - & - & - & - & - \\
\hline 16 & 0 & 0 & 0 & 0 & 0 \\
\hline 17 & 1 & 0 & 0 & 0 & 1 \\
\hline 18 & 0 & 0 & 0 & 0 & 0 \\
\hline 19 & 1 & 0 & 0 & 0 & 1 \\
\hline 20 & 0 & 0 & 0 & 0 & 0 \\
\hline 21 & 1 & 0 & 0 & 0 & 1 \\
\hline 22 & 1 & 0 & 0 & 0 & 1 \\
\hline 23 & 0 & 0 & 0 & 0 & 0 \\
\hline 24 & 0 & 0 & 0 & 0 & 0 \\
\hline Total & 11 & 2 & 1 & 1 & 15 \\
\hline
\end{tabular}

Table A4. Irrelevant descriptors identified in the sediment monitoring.

\begin{tabular}{lccccc}
\hline ID & Metals & Hydrocarbons & Sulphurus & $\begin{array}{c}\text { Surface Carbon } \\
\text { Particles }\end{array}$ & Total \\
\hline 1 & - & - & - & - & - \\
2 & 0 & 0 & 0 & 0 & 0 \\
3 & 0 & 0 & 0 & 0 & 0 \\
4 & 0 & 0 & 0 & 0 & 0 \\
5 & 0 & 0 & 0 & 0 & 0 \\
6 & 0 & 0 & 0 & 0 & 0 \\
7 & - & - & - & - & - \\
8 & 1 & 0 & 1 & 1 & 0 \\
9 & 0 & 0 & 0 & 0 & 0 \\
10 & 0 & 0 & 0 & 0 & 2 \\
11 & 1 & 1 & 0 & 0 & 0 \\
12 & 0 & 1 & 0 & 0 & 0 \\
13 & 0 & 0 & 0 & 0 & - \\
14 & 0 & 0 & 0 & - & 2 \\
15 & - & - & - & 0 & 0 \\
16 & 1 & 1 & 0 & 0 & 0 \\
17 & 0 & 0 & 0 & 0 & 0 \\
18 & 0 & 0 & 0 & 0 & 3 \\
19 & 0 & 0 & 0 & 1 & 1 \\
20 & 1 & 0 & 1 & 0 & 0 \\
21 & 0 & 1 & 0 & 0 & 0 \\
22 & 0 & 0 & 0 & 0 & 0 \\
23 & 0 & 0 & 0 & 0 & 0 \\
24 & 1 & 0 & 0 & 0 & 0 \\
\hline Total & $\mathbf{5}$ & 0 & 0 & 0 & 0 \\
\hline & & 0 & 0 & 0 & 0 \\
\hline
\end{tabular}


Table A5. Others irrelevant descriptors identified.

\begin{tabular}{cccc}
\hline ID & Current Monitoring & Sea State/Wind & Total \\
\hline 1 & - & - & - \\
2 & 0 & 0 & 0 \\
3 & 0 & 0 & 0 \\
4 & 0 & 0 & 0 \\
5 & 0 & 0 & 0 \\
6 & 0 & 0 & 1 \\
7 & - & - & - \\
8 & 0 & 0 & 0 \\
9 & 0 & 0 & 0 \\
10 & 0 & 1 & 0 \\
11 & 1 & 0 & 1 \\
12 & 0 & 0 & 0 \\
13 & 0 & 0 & 0 \\
14 & 0 & 0 & 0 \\
15 & - & - & - \\
16 & 0 & 0 & 0 \\
17 & 0 & 0 & 0 \\
18 & 0 & 0 & 0 \\
19 & 1 & 1 & 2 \\
20 & 0 & 0 & 0 \\
21 & 0 & 0 & 0 \\
22 & 0 & 0 & 0 \\
23 & 0 & 0 & 0 \\
24 & 0 & 0 & 0 \\
\hline Total & 3 & $\mathbf{2}$ & \\
\hline
\end{tabular}

\section{References}

1. Shahzad, M.W.; Burhan, M.; Ang, L.; Ng, K.C. Energy-water-environment nexus underpinning future desalination sustainability. Desalination 2017, 413, 52-64. [CrossRef]

2. Mata-Torres, C.; Escobar, R.A.; Cardemil, J.M.; Simsek, Y.; Matute, J.A. Solar polygeneration for electricity production and desalination: Case studies in Venezuela and northern Chile. Renew. Energy 2017, 101, 387-398. [CrossRef]

3. Bonelli, S.; Vicuña, S.; Meza, F.J.; Gironás, J.; Barton, J. Incorporating climate change adaptation strategies in urban water supply planning: the case of central Chile. J. Water Clim. Chang. 2014, 5, 357-376. [CrossRef]

4. Ancapichun, S. Variability of the Southeast Pacific Subtropical Anticyclone and its impact on sea surface temperature off north-central Chile. Ciencias Mar. 2015, 41, 1-20. [CrossRef]

5. Molinos-Senante, M.; González, D. Evaluation of the economics of desalination by integrating greenhouse gas emission costs: An empirical application for Chile. Renew. Energy 2019, 133, 1327-1337. [CrossRef]

6. Mineria, M. de Consumo de agua en la minera de cobre. 2012, pp. 1-36. Available online: http://www. aih-cl.org/articulos/Consumo-de-agua-en-la-mineria-del\%20cobre-COCHILCO-(2011).pdf (accessed on 20 April 2019).

7. Portillo, E.; Ruiz de la Rosa, M.; Louzara, G.; Ruiz, J.M.; Marín-Guirao, L.; Quesada, J.; González, J.C.; Roque, F.; González, N.; Mendoza, H. Assessment of the abiotic and biotic effects of sodium metabisulphite pulses discharged from desalination plant chemical treatments on seagrass (Cymodocea nodosa) habitats in the Canary Islands. Mar. Pollut. Bull. 2014, 80, 222-233. [CrossRef]

8. Fernández-Torquemada, Y.; Gónzalez-Correa, J.M.; Loya, A.; Ferrero, L.M.; Díaz-Valdés, M.; Sánchez-Lizaso, J.L. Dispersion of brine discharge from seawater reverse osmosis desalination plants. Desalin. Water Treat. 2009, 5, 137-145. [CrossRef]

9. Fernández-Torquemada, Y.; González-Correa, J.M.; Sánchez-Lizaso, J.L. Echinoderms as indicators of brine discharge impacts. Desalin. Water Treat. 2013, 51, 567-573. [CrossRef] 
10. De-la-Ossa-Carretero, J.A.; Del-Pilar-Ruso, Y.; Loya-Fernández, A.; Ferrero-Vicente, L.M.; Marco-Méndez, C.; Martinez-Garcia, E.; Giménez-Casalduero, F.; Sánchez-Lizaso, J.L. Bioindicators as metrics for environmental monitoring of desalination plant discharges. Mar. Pollut. Bull. 2016, 103, 313-318. [CrossRef]

11. Del-Pilar-Ruso, Y.; Martinez-Garcia, E.; Giménez-Casalduero, F.; Loya-Fernández, A.; Ferrero-Vicente, L.M.; Marco-Méndez, C.; de-la-Ossa-Carretero, J.A.; Sánchez-Lizaso, J.L. Benthic community recovery from brine impact after the implementation of mitigation measures. Water Res. 2015, 70, 325-336. [CrossRef]

12. Petersen, K.L.; Frank, H.; Paytan, A.; Bar-Zeev, E. Impacts of Seawater Desalination on Coastal Environments. In Sustainable Desalination Handbook: Plant Selection, Design and Implementation; Gude, V.G., Ed.; Butterworth-Heinemann: Oxford, UK, 2018; pp. 437-463.

13. Roberts, D.A.; Johnston, E.L.; Knott, N.A. Impacts of desalination plant discharges on the marine environment: A critical review of published studies. Water Res. 2010, 44, 5117-5128. [CrossRef] [PubMed]

14. Lacy, S.N.; Meza, F.J.; Marquet, P.A. Can environmental impact assessments alone conserve freshwater fish biota? Review of the Chilean experience. Environ. Impact Assess. Rev. 2017, 63, 87-94. [CrossRef]

15. de la Maza, C.L. NEPA's influence in developing countries: The Chilean case. Environ. Impact Assess. Rev. 2001, 21, 169-179. [CrossRef]

16. Sadhwani Alonso, J.J.; Melián-Martel, N. Environmental Regulations-Inland and Coastal Desalination Case Studies. In Sustainable Desalination Handbook: Plant Selection, Design and Implementation; Gude, V.G., Ed.; Butterworth-Heinemann: Oxford, UK, 2018; pp. 403-435.

17. Sola, I.; Zarzo, D.; Sánchez-Lizaso, J.L. Evaluating environmental requirements for the management of brine discharges in Spain. Desalination 2019, 471, 114132. [CrossRef]

18. Mezher, T.; Fath, H.; Abbas, Z.; Khaled, A. Techno-economic assessment and environmental impacts of desalination technologies. Desalination 2011, 266, 263-273. [CrossRef]

19. Kress, N. Policy and Regulations for Seawater Desalination. In Mar. Impacts Seawater Desalin: Science, Management, and Policy; Kress, N., Ed.; Elsevier: Amsterdam, The Netherlands, 2019; pp. 135-163. [CrossRef]

20. Sánchez-Lizaso, J.L.; Romero, J.; Ruiz, J.; Gacia, E.; Buceta, J.L.; Invers, O.; Fernández Torquemada, Y.; Mas, J.; Ruiz-Mateo, A.; Manzanera, M. Salinity tolerance of the Mediterranean seagrass Posidonia oceanica: recommendations to minimize the impact of brine discharges from desalination plants. Desalination 2008, 221, 602-607. [CrossRef]

21. Hurlbert, S.H. Pseudoreplication and the Design of Ecological Field Experiments. Ecol. Monogr. 1984, 54, 187-211. [CrossRef]

22. Underwood, A.J. On Beyond BACI: Sampling Designs that Might Reliably Detect Environmental Disturbances. Ecol. Appl. 1994, 4, 3-15. [CrossRef]

23. Team, R.C. R: A Language and Environment for Statistical Computing; R Foundation for Statistical Computing: Vienna, Austria, 2013.

24. Meneses, M.; Pasqualino, J.C.; Céspedes-Sánchez, R.; Castells, F. Alternatives for reducing the environmental impact of the main residue from a desalination plant. J. Ind. Ecol. 2010, 14, 512-527. [CrossRef]

25. Valdés-Pineda, R.; Pizarro, R.; García-Chevesich, P.; Valdés, J.B.; Olivares, C.; Vera, M.; Balocchi, F.; Pérez, F.; Vallejos, C.; Fuentes, R.; et al. Water governance in Chile: Availability, management and climate change. J. Hydrol. 2014, 519, 2538-2567. [CrossRef]

26. Aguilera, M.A.; Aburto, J.A.; Bravo, L.; Broitman, B.R.; García, R.A.; Gaymer, C.F.; Gelcich, S.; López, B.A.; Montecino, V.; Pauchard, A.; et al. Chile: Environmental Status and Future Perspectives. In World Seas: An Environmental Evaluation, Volume I: Europe, the Americas and West Africa; Sheppard, C., Ed.; Academic Press: Cambridge, MA, USA, 2019; pp. 673-702.

27. Loya-Fernández, Á.; Ferrero-vicente, L.M.; Marco-méndez, C.; Martínez-garcía, E.; Jacobo, J.; Sánchez-lizaso, J.L. Quantifying the efficiency of a mono-port diffuser in the dispersion of brine discharges. Desalination 2018, 431, 27-34.

28. Clark, G.F.; Knott, N.A.; Miller, B.M.; Kelaher, B.P.; Coleman, M.A.; Ushiama, S.; Johnston, E.L. First large-scale ecological impact study of desalination outfall reveals trade-offs in effects of hypersalinity and hydrodynamics. Water Res. 2018, 145, 757-768. [CrossRef] [PubMed]

29. De-la-Ossa-Carretero, J.A.; Del-Pilar-Ruso, Y.; Loya-Fernández, A.; Ferrero-Vicente, L.M.; Marco-Méndez, C.; Martinez-Garcia, E.; Sánchez-Lizaso, J.L. Response of amphipod assemblages to desalination brine discharge: Impact and recovery. Estuar. Coast. Shelf Sci. 2016, 172, 13-23. [CrossRef] 
30. Marín-Guirao, L.; Sandoval-Gil, J.M.; Bernardeau-Esteller, J.; Ruíz, J.M.; Sánchez-Lizaso, J.L. Responses of the Mediterranean seagrass Posidonia oceanica to hypersaline stress duration and recovery. Mar. Environ. Res. 2013, 84, 60-75. [CrossRef] [PubMed]

31. Sandoval-Gil, J.M.; Marín-Guirao, L.; Ruiz, J.M. Tolerance of Mediterranean seagrasses (Posidonia oceanica and Cymodocea nodosa) to hypersaline stress: Water relations and osmolyte concentrations. Mar. Biol. 2012, 159, 1129-1141. [CrossRef]

32. Cambridge, M.L.; Zavala-Perez, A.; Cawthray, G.R.; Mondon, J.; Kendrick, G.A. Effects of high salinity from desalination brine on growth, photosynthesis, water relations and osmolyte concentrations of seagrass Posidonia australis. Mar. Pollut. Bull. 2017, 115, 252-260. [CrossRef]

33. Wernberg, T.; Krumhansl, K.; Filbee-Dexter, K.; Pedersen, M.F. Status and Trends for the World's Kelp Forests. In World Seas: An Environmental Evaluation, Volume I: Europe, the Americas and West Africa; Sheppard, C., Ed.; Academic Press: Cambridge, MA, USA, 2019; pp. 57-78.

(C) 2019 by the authors. Licensee MDPI, Basel, Switzerland. This article is an open access article distributed under the terms and conditions of the Creative Commons Attribution (CC BY) license (http://creativecommons.org/licenses/by/4.0/). 